\title{
Transient dilutional acidosis but no lactic acidosis upon cardiopulmonary bypass in patients undergoing coronary artery bypass grafting
}

\author{
Johanna Katharina Teloh ${ }^{1}$, Daniel-Sebastian Dohle², Serhat Sönmez ${ }^{1}$, Konstantinos Tsagakis², \\ Rabea Verhaegh ${ }^{1}$, Miriam Petersen ${ }^{3}$, Heinz Jakob ${ }^{2}$, Herbert de Groot ${ }^{1}$
}

\author{
${ }^{1}$ Institute of Physiological Chemistry, University Hospital Essen, University \\ of Duisburg-Essen, Essen, Germany \\ ${ }^{2}$ Department of Thoracic and Cardiovascular Surgery, University Hospital Essen, \\ Essen, Germany \\ 3̈̈berörtliche Berufsausübungsgemeinschaft MVZ Dr. Eberhard und Partner, \\ Dortmund, Germany
}

Submitted: 26 May 2015

Accepted: 19 June 2015

Arch Med Sci 2017; 13, 3: 585-590

DOI: $10.5114 /$ aoms.2016.58144

Copyright $\odot 2016$ Termedia \& Banach

\section{Abstract}

Introduction: Dilutional acidosis may result from the introduction of a large fluid volume into the patients' systemic circulation, resulting in a considerable dilution of endogenous bicarbonate in the presence of a constant carbon dioxide partial pressure. Its significance or even existence, however, has been strongly questioned. Blood gas samples of patients operated on with standard cardiopulmonary bypass (CPB) were analyzed in order to provide further evidence for the existence of dilutional acidosis.

Material and methods: Between 07/2014 and 10/2014, a total of 25 consecutive patients scheduled for elective isolated coronary artery bypass grafting with CPB were enrolled in this prospective observational study. Blood gas samples taken regularly after CPB initiation were analyzed for dilutional effects and acid-base changes.

Results: After CPB initiation, hemoglobin concentration dropped from an average initial value of $12.8 \mathrm{~g} / \mathrm{dl}$ to $8.8 \mathrm{~g} / \mathrm{dl}$. Before the beginning of CPB, the mean value of the patients' $\mathrm{pH}$ and base excess (BE) value averaged 7.41 and $0.5 \mathrm{mEq} / \mathrm{l}$, respectively. After the onset of $\mathrm{CPB}, \mathrm{pH}$ and $\mathrm{BE}$ values significantly dropped to a mean value of $7.33(p<0.0001)$ and $-3.3 \mathrm{mEq} / \mathrm{l}$ $(p<0.0001)$, respectively, within the first $20 \mathrm{~min}$. In the following period during CPB they recovered to 7.38 and $-0.5 \mathrm{mEq} / \mathrm{l}$, respectively, on average. Patients did not show overt lactic acidosis.

Conclusions: The present data underline the general existence of dilutional acidosis, albeit very limited in its duration. In patients undergoing coronary artery bypass grafting it seems to be the only obvious disturbance in acidbase homeostasis during CPB.

Key words: metabolic acidosis, priming solution, cardioplegia, cardioplegic solution.

\section{Introduction}

According to the classical dilution concept, the administration of large volumes of saline fluids to the patients' systemic circulation causes the dilution of serum bicarbonate [1-4], leading to a disturbance in

\author{
Corresponding author: \\ Johanna Teloh \\ Institute of Physiological \\ Chemistry \\ University Hospital Essen \\ University of Duisburg-Essen \\ Hufelandstrasse 55 \\ 45122 Essen, Germany \\ Phone: +49 2017234107 \\ E-mail: johanna.teloh@ \\ uk-essen.de
}


acid-base homeostasis termed dilutional acidosis, which was first described by Peters and van Slyke in 1931 [5]. The reason for its development is assumed to lie in the open carbon dioxide/bicarbonate-buffer system where the buffer base bicarbonate is diluted upon massive infusion, whereas in the presence of a constant carbon dioxide partial pressure the buffer acid is not $[6,7]$. Currently, dilutional acidosis constitutes one of the most controversially discussed topics in acid-base homeostasis [3, 4, 8-11]. Not only has its magnitude been discussed, but even its fundamental existence has been questioned.

In the vast majority of clinical cases, infusion is too slow to cause marked dilutional effects. On the other hand, in patients undergoing operations involving a cardiopulmonary bypass (CPB) large fluid volumes may be introduced into the systemic circulation within a short period after CPB initiation, resulting in very rapid dilution of intravascular bicarbonate, proteins and electrolytes. In our institution, it is local practice to prime the heartlung machine with about 1.1 I of $\mathrm{NaCl}$ solution. For induction of cardiac arrest also more than 1 I of cardioplegic solution may be applied. Therefore, CPB initiation constitutes an optimal model for studying dilutional acidosis.

In the phase of $C P B$, rising lactate concentrations are frequently described likewise [12-14]. Therefore, a dilutional acidosis might be sometimes covered by a concomitant lactic acidosis. Hence, we analyzed the current data under this aspect as well.

\section{Material and methods}

\section{Study design and patient population}

Between 07/2014 and 10/2014, a total of 25 patients scheduled for elective isolated coronary artery bypass grafting (CABG) with CPB were enrolled in the prospective non-randomized observational study at the Department of

Table I. Characteristics of 25 patients who underwent coronary artery bypass grafting

\begin{tabular}{|lc|}
\hline Variable & $\begin{array}{c}\text { Median } \\
(25 \% \text { and } 75 \% \\
\text { quartile })\end{array}$ \\
\hline Age [years] & $71(60 ; 76)$ \\
\hline Height $[\mathrm{cm}]$ & $173(168 ; 180)$ \\
\hline Weight $[\mathrm{kg}]$ & $88(79 ; 92)$ \\
\hline Body surface area $\left[\mathrm{m}^{2}\right]$ & $2.01(1.87 ; 2.13)$ \\
\hline Body mass index $\left[\mathrm{kg} / \mathrm{m}^{2}\right]$ & $28.2(26.03 ; 32.28)$ \\
\hline Cardiopulmonary bypass time $[\mathrm{min}]$ & $84(71 ; 118)$ \\
\hline Cross-clamp time $[\mathrm{min}]$ & $53(40 ; 65)$ \\
\hline
\end{tabular}

Thoracic and Cardiovascular Surgery, University Hospital Essen. The study was approved by the Medical Ethics Committee of the University Hospital Essen and conforms to the principles of the Declaration of Helsinki. All individuals gave written informed consent. Adults operated on for an elective isolated coronary heart disease by standard CABG at our center were included. Exclusion criteria were acute myocardial infarction with or without ST-elevation, cardiogenic shock, concomitant cardiac diseases and procedures, preoperative acidosis or participation in other clinical trials.

The standard CPB technique was used with ascending aortic and two-stage venous cannulation. Heparin was administered to achieve an activated coagulation time > 400 s. Cardiopulmonary bypass was conducted with hemodilution (solely $0.9 \% \mathrm{NaCl}, 1.1$ I priming volume on average), mild hypothermia $\left(32^{\circ} \mathrm{C}\right)$ and membrane oxygenation (Medtronic Affinity fusion oxygenator system with integrated arterial filter and venous reservoir; Medtronic, Santa Rosa California). Myocardial protection was achieved using antegrade cold crystalloid Bretschneider cardioplegia (Custodiol, Dr. Franz Koehler Chemie, Bensheim, Germany, 1.6 I on average), given once for initial cardiac arrest, supplemented by topical cooling, and single aortic cross-clamping for all distal anastomoses. The internal left thoracic artery and saphenous veins were the preferred grafts.

\section{Data collection}

The duration of CPB and aortic cross-clamping as well as the volume of the priming fluid was documented. Blood gas samples were routinely taken from the CPB and analyzed (ABL800 FLEX, Radiometer $\mathrm{GmbH}$, Willich, Germany) for hemoglobin, $\mathrm{pH}$ value, electrolytes $\left(\mathrm{Na}^{+}, \mathrm{K}^{+}, \mathrm{Ca}^{2+}, \mathrm{Cl}^{-}\right)$, glucose, lactate, bicarbonate, and base excess. Moments of withdrawal were not controlled, but were standardized by hospital practice (half-hourly).

\section{Statistical analysis}

Comparisons among different time points were performed using one-way independent analysis of variance (ANOVA), followed by Fisher (LSD) post hoc analysis. A $p$-value $<0.0001$ was considered significant.

\section{Results}

Twenty-five patients were included in the present observational study. Of these, $76 \%$ were of male gender. The median number of grafts per patient was three. Further characteristics such as age, weight, height, body surface area, body mass index, CPB time and cross-clamp time are 
A

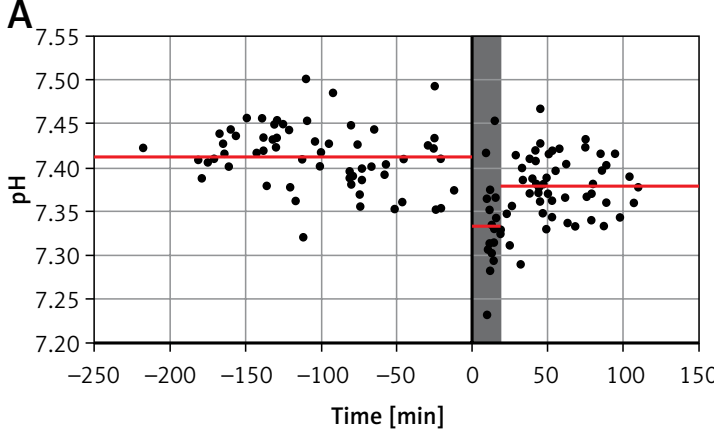

C

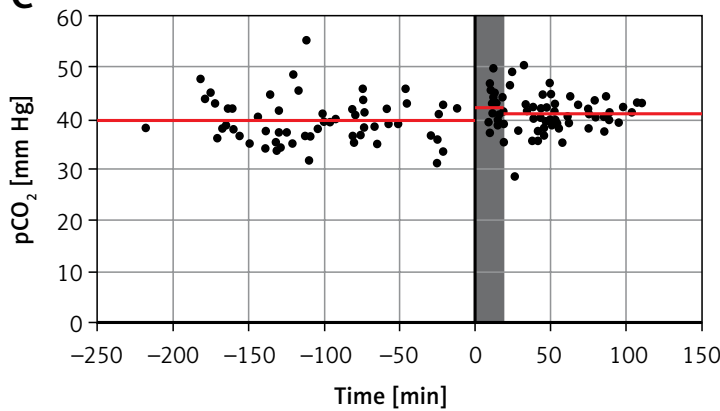

B

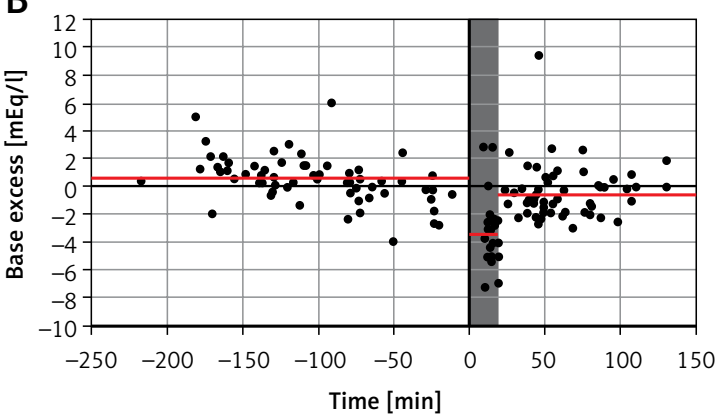

D

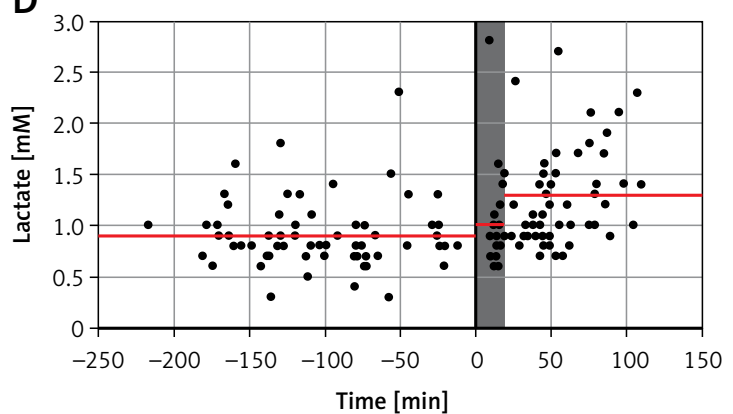

Figure 1. Changes in $\mathrm{pH}, \mathrm{BE}, \mathrm{pCO}_{2}$ and lactate from the beginning of the operation until the end of $\mathrm{CPB} . \mathrm{A}-\mathrm{pH}$, $\mathbf{B}-\mathrm{BE}, \mathbf{C}-\mathrm{pCO}_{2}$, D - lactate. Documentation of parameters begins with the start of the operation. Time point zero characterizes onset of CPB. The period of CPB is divided into two intervals: 0-20 min (shaded in grey) and the remaining time (20 min until the end of CPB). The red line represents the mean value in the respective interval

presented in Table I. On average, patients received $1.1 \pm 0.1$ I priming fluid $(\mathrm{NaCl}), 1.6 \pm 0.2$ I cardioplegic (Bretschneider) solution and $102 \pm 31 \mathrm{mmol}$ bicarbonate based on individual demand.

After the start of CPB, the patients' hemoglobin concentration dropped by $30 \%$ from an average initial value of $12.8 \mathrm{~g} / \mathrm{dl}$ to $8.8 \mathrm{~g} / \mathrm{dl}$.

Before the beginning of CPB, the mean value of the patients' $\mathrm{pH}$ was 7.41 and was therefore close to the standard value of 7.40 (Figure 1, Table II). As regards the course of $\mathrm{pH}$ and $\mathrm{BE}$ value, see also Figure 2, which presents the progression in a typical patient. After the onset of CPB, the $\mathrm{pH}$ significantly dropped to a mean value of 7.33 within the first $20 \mathrm{~min}$. In the following period during CPB, it recovered to 7.38 on average. Before the start of CPB, the base excess (BE) was $0.5 \mathrm{mEq} / \mathrm{l}$ and was therefore within the physiological range of $\pm 2 \mathrm{mEq} / \mathrm{l}$ (Figures 1 and 2, Table II). Within the first 20 min after the beginning of CPB, it significantly decreased to a mean value of $-3.3 \mathrm{mEq} / \mathrm{l}$. In the remaining period of $\mathrm{CPB}$, it recovered to a mean value of $-0.5 \mathrm{mEq} / \mathrm{l}$ again. Within the first $20 \mathrm{~min}$ of CPB, patients received $54 \mathrm{mmol}$ bicarbonate on average by the perfusionist (see also Figure 2). In the remaining time during $\mathrm{CPB}$, they received additional bicarbonate averaging $41 \mathrm{mmol}$. From the beginning of the operation until the end of $C P B$, carbon dioxide partial pressure $\left(\mathrm{pCO}_{2}\right)$ was constantly around the physiological standard value of $40 \mathrm{~mm} \mathrm{Hg}$ (39.3 mm Hg before CPB, $41.7 \mathrm{~mm} \mathrm{Hg}$
Table II. Mean values of $\mathrm{pH}, \mathrm{BE}, \mathrm{pCO}_{2}$ and lactate per interval

\begin{tabular}{|c|c|c|}
\hline Parameter & Interval & Mean \pm SD \\
\hline \multirow[t]{3}{*}{$\mathrm{pH}$} & Start of operation - 0 min & $7.41 \pm 0.04$ \\
\hline & $0 \mathrm{~min}-20 \mathrm{~min}$ & $7.33 \pm 0.05^{\star * *}$ \\
\hline & $20 \mathrm{~min}-$ end of CPB & $7.38 \pm 0.04$ \\
\hline \multirow{3}{*}{$\begin{array}{l}\mathrm{BE} \\
{[\mathrm{mEq} / \mathrm{l}]}\end{array}$} & Start of operation $-0 \mathrm{~min}$ & $0.5 \pm 2.6$ \\
\hline & $0 \min -20 \min$ & $-3.3 \pm 2.1^{* * *}$ \\
\hline & $20 \mathrm{~min}$ - end of CPB & $-0.5 \pm 1.7$ \\
\hline \multirow{3}{*}{$\begin{array}{l}\mathrm{pCO}_{2} \\
{[\mathrm{~mm} \mathrm{Hg} \mathrm{Hg}}\end{array}$} & Start of operation - 0 min & $39.3 \pm 4.4$ \\
\hline & $0 \mathrm{~min}-20 \mathrm{~min}$ & $41.7 \pm 3.3$ \\
\hline & $20 \mathrm{~min}$ - end of CPB & $40.4 \pm 3.6$ \\
\hline \multirow{3}{*}{$\begin{array}{l}\text { Lactate } \\
{[\mathrm{mM}]}\end{array}$} & Start of operation - $0 \mathrm{~min}$ & $0.9 \pm 0.3$ \\
\hline & $0 \min -20 \min$ & $1.0 \pm 0.5$ \\
\hline & $20 \mathrm{~min}-$ end of CPB & $1.3 \pm 0.5$ \\
\hline
\end{tabular}

"O min" characterizes the onset of $C P B .{ }^{* * *} p<0.0001$ compared with the interval "start of operation - 0 min" and " $20 \mathrm{~min}$ - end of CPB", respectively.

within the first $20 \mathrm{~min}$ of $\mathrm{CPB}, 40.4 \mathrm{~mm} \mathrm{Hg}$ in the residual time of $C P B$; Figure 1, Table II).

The average value for the patients' lactate concentration was $0.9 \mathrm{mM}$ before onset of CPB, $1.0 \mathrm{mM}$ within the first 20 min after the beginning of $C P B$, and $1.3 \mathrm{mM}$ within the remaining time of CPB (Figure 1, Table II). 

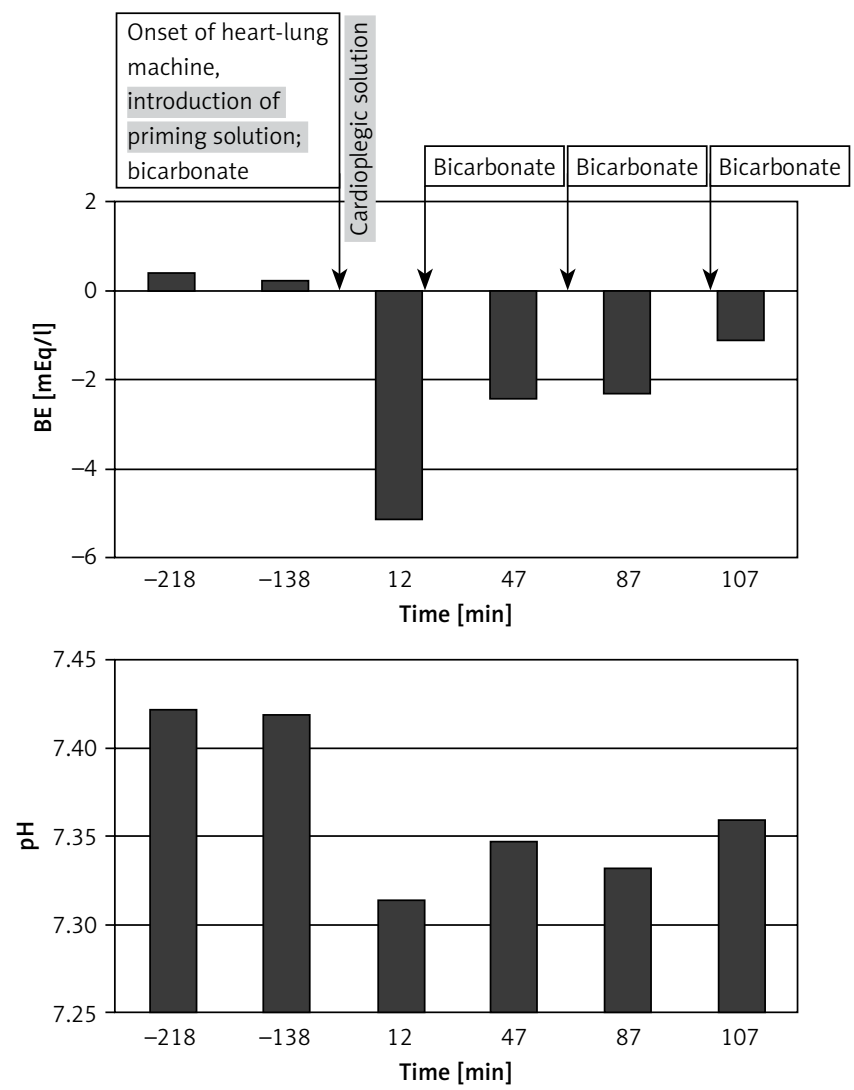

Figure 2. Changes in $\mathrm{pH}$ and $\mathrm{BE}$ in a typical patient from the beginning of the operation until the end of $\mathrm{CPB}$. With the onset of the heart-lung machine at time point zero, the patient received 1.1 I of $\mathrm{NaCl}$ as priming fluid. Subsequently, he received $1.8 \mathrm{I}$ of Bretschneider solution for cardioplegic arrest. For neutralization of dilutional acidosis, bicarbonate was administered four times in the amounts of $50 \mathrm{mmol}, 40 \mathrm{mmol}, 20 \mathrm{mmol}$ and $30 \mathrm{mmol}$

\section{Discussion}

The current observational study yielded three main results. First, there occurs dilutional acidosis after the onset of CPB as indicated by a simultaneous and significant drop in $\mathrm{pH}$ and $\mathrm{BE}$ (Figures 1, 2, Table II). Second, this dilutional acidosis is of limited duration. Third, there is no overt lactic acidosis during the whole phase of CPB.

In the present patients, dilutional acidosis should result from the rapid administration of

Table III. Composition of the cardioplegic Bretschneider solution employed in this study

\begin{tabular}{|lc|}
\hline Substance & Molarity [mM] \\
\hline $\mathrm{Na}^{+}$ & 15.0 \\
\hline $\mathrm{K}^{+}$ & 10.0 \\
\hline $\mathrm{Mg}^{2+}$ & 4.0 \\
\hline $\mathrm{Ca}^{2+}$ & 0.015 \\
\hline Histidine & 198.0 \\
\hline Tryptophan & 2.0 \\
\hline a-Ketoglutarate & 1.0 \\
\hline Mannitol & 30.0 \\
\hline
\end{tabular}

both the priming and the cardioplegic solution. As priming fluid, $0.9 \% \mathrm{NaCl}$ solution was employed according to present institutional practice. Due to the absence of bicarbonate in this solution, endogenous bicarbonate is heavily diluted after administration, thus resulting in the development of dilutional acidosis. The Bretschneider solution employed for cardioplegia contains mostly electrolytes and with histidine and tryptophan two different amino acids (Table III). As regards dilutional acidosis, this solution must be treated as a salt solution like the $0.9 \% \mathrm{NaCl}$ solution used as the priming fluid, since it is also devoid of bicarbonate and contains only $1 \mathrm{mM} \alpha$-ketoglutarate as a precursor thereof. The histidine's impact to act as a proton accepting or donating buffer is currently uncertain but seems to be quantitatively negligible in relation to the degree of dilutional acidosis. Data from a few past studies with patients undergoing elective $C A B G$ in the majority of cases [12, $15,16]$ also indicate the presence of a metabolic acidosis in terms of a dilutional acidosis, although none of these studies evaluated the data explicitly for dilutional acidosis resulting from the inherent characteristics of CPB, and blood gas analyses were performed only in a limited amount (before $\mathrm{CPB}$, sometimes 2 min after onset of CPB or during 
rewarming, and at the end of CPB or even solely in the postoperative phase).

In the current study, sodium bicarbonate was given intraoperatively depending on the individual demand based on the magnitude of the patients' metabolic acidosis. This bicarbonate administration should have influenced the magnitude of the dilutional acidosis observed here. In accordance with the drop in the hemoglobin concentration after the onset of CPB (measured within the first $20 \mathrm{~min}$ ) by approximately $30 \%$, one should expect the BE to also drop by $30 \%$ on average, and thus to be situated around $-7.0 \mathrm{mEq} / \mathrm{l}$, which is far more negative than the measured value of $-3.3 \mathrm{mEq} / \mathrm{l}$. Therefore, without bicarbonate administration, dilutional acidosis would presumably have been even more prominent. Moreover, $\mathrm{pH}$ and $\mathrm{BE}$ values displayed a restriction of dilutional acidosis to a short time interval after onset of CPB (i.e. approximately 20 min in the present study). This short duration most likely also results from bicarbonate administration. Without bicarbonate administration, the phase of dilutional acidosis would probably have been longer. Nevertheless, dilutional acidosis should always possess a transient character due to general compensatory mechanisms such as a high intracellular buffer capacity, the generation of new bicarbonate from bone sources as well as renal mechanisms $[4,11,17,18]$.

The temporal limitation of dilutional acidosis based on both bicarbonate administration and physiologic compensatory mechanisms requires a high infusion rate paired with a large fluid volume for its manifestation such as during CPB initiation. These findings are in accordance with those of Shires and Holman that indicate an infusion rate of at least $300 \mathrm{ml} / \mathrm{min}$ [19] to produce marked dilutional effects in an experimental study in dogs. The obviously high infusion rate required for the occurrence of dilutional acidosis is not attainable by usual infusions. Additionally, bicarbonate administration and too large time intervals between single blood gas analyses might be the reasons why most investigators have not observed overt dilutional acidosis in former studies and possibly therefore have denied its existence [10]. Nevertheless, clinical situations beyond the usage of CPB do exist in which a large fluid volume has to be substituted which may also lead to dilutional acidosis, as demonstrated in case reports $[3,10]$.

For the description of acid-base disturbances, we chose the traditional concept based on the equation of Henderson-Hasselbalch and not the alternative one from Stewart [20]. In our opinion, the mechanistic formulation of the traditional concept reflects the underlying acid-base phenomenology more appropriately $[6,21]$. Nevertheless, the Stewart approach also predicts the development of a metabolic acidosis under the conditions given here, terming it hyperchloremic acidosis.

The perioperative increase of lactate during cardiac operations with CPB is frequently described. Studies with patient collectives operated on for complex diseases resulting in long CPB and cross-clamp times report a distinct rise in systemic lactate concentration during CPB [12-14]. Other studies with mean cross-clamp times of only about 50 min merely revealed very moderate increases in lactate concentration [22, 23]. Accordingly, correlations of both CPB and cross-clamp time with a rise in arterial lactate concentration have been reported $[24,25]$. In the present study, lactate production during CPB was small. Measured values of lactate concentration slightly rose (Figure 1) but distinctly stayed below $2 \mathrm{mM}$, the threshold value for the presence of a lactic acidosis [26]. Since only patients with isolated CABG procedures were included in the present study, the cross-clamp times were moderate (Table I) and the findings regarding the lactate concentration are comparable to the literature.

Acidosis in general may have serious consequences for the organism, including systemic vasodilation and catecholamine resistance [27-29]. As a consequence, organ perfusion may be aggravated. Although transient, such alterations should also be produced by dilutional acidosis. Additionally, during CPB, the non-pulsatile perfusion pressure of only $50 \mathrm{~mm} \mathrm{Hg}$ to $60 \mathrm{~mm} \mathrm{Hg}$ is under suspicion to favor diminished organ perfusion with concomitant tissue hypoxia. Therefore, awareness of the existence of dilutional acidosis and its chronological sequence should help to improve therapeutic strategies.

There are some limitations of the present study. Due to its observational character, withdrawal of blood for analysis, and the volumes of the priming, cardioplegic as well as bicarbonate solutions, were not controlled but were standardized by hospital practice. Furthermore, data were collected within a single center, and thus only one particular pump prime $(0.9 \% \mathrm{NaCl})$ was evaluated although compositions of priming solutions vary markedly among different locations at present [30]. But our intention was not to appraise different solutions or mixtures thereof, but instead to prove the general existence of dilutional acidosis. As long as the priming solution displays a bicarbonate concentration that is below the physiologic concentration, the occurrence of dilutional acidosis is supposed to be independent of the composition of the respective priming solution, since the transient dilutional effect occurs immediately after introduction. At this point, any included metabolizable anions could not have been metabolized yet. 
In conclusion, in patients undergoing CABG, we observed no significant lactic acidosis but a transient dilutional acidosis that was the only obvious disturbance of acid-base homeostasis during the phase of CPB. Generally, dilutional acidosis can occur after administration of bicarbonate free volume, but its clinical relevance is limited to situations with rapid and massive volume substitution such as at CPB initiation (priming plus cardioplegic solution) and can be treated by bicarbonate administration.

\section{Conflict of interest}

The authors declare no conflict of interest.

\section{References}

1. Shires GT, Holman J. Dilution acidosis. Am J Med 1948; 4: 467.

2. Asano S, Kato E, Yamauchi M, Ozawa Y, Iwasa M. The mechanism of acidosis caused by infusion of saline solution. Lancet 1966; 1: 1245-6.

3. Goodkin DA, Raja RM, Saven A. Dilutional acidosis. South Med J 1990; 83: 354-5.

4. Garella S, Chang BS, Kahn SI. Dilution acidosis and contraction alkalosis: review of a concept. Kidney Int 1975; 8: 279-83.

5. Peters JP, van Slyke DD. Quantitative Clinical Chemistry: Interpretations. $1^{\text {st }}$ ed. Williams and Wilkins, Baltimore 1931.

6. Doberer D, Funk GC, Kirchner K, Schneeweiss B. A critique of Stewart's approach: the chemical mechanism of dilutional acidosis. Intensive Care Med 2009; 35 2173-80.

7. Gattinoni L, Carlesso E, Maiocchi G, Polli F, Cadringher P. Dilutional acidosis: where do the protons come from? Intensive Care Med 2009; 35: 2033-43.

8. Doberer D, Funk GC, Schneeweiss B. Dilutional acidosis: an endless story of confusion. Crit Care Med 2003; 31: 337-8.

9. Garella S, Tzamaloukas AH, Chazan JA. Effect of isotonic volume expansion on extracellular bicarbonate stores in normal dogs. Am J Physiol 1973; 225: 628-36.

10. Mathes DD, Morell RC, Rohr MS. Dilutional acidosis: is it a real clinical entity? Anesthesiology 1997; 86: 501-3.

11. Rosenbaum BJ, Makoff DL, Maxwell MH. Acid-base and electrolyte changes induced by acute isotonic saline infusion in the nephrectomized dog. J Lab Clin Med 1969; 74: 427-35.

12. Hugot P, Sicsic JC, Schaffuser A, et al. Base deficit in immediate postoperative period of coronary surgery with cardiopulmonary bypass and length of stay in intensive care unit. Intensive Care Med 2003; 29: 257-61.

13. Shinde SB, Golam KK, Kumar P, Patil ND. Blood lactate levels during cardiopulmonary bypass for valvular heart surgery. Ann Card Anaesth 2005; 8: 39-44.

14. Munoz R, Laussen PC, Palacio G, Zienko L, Piercey G, Wessel DL. Changes in whole blood lactate levels during cardiopulmonary bypass for surgery for congenital cardiac disease: an early indicator of morbidity and mortality. J Thorac Cardiovasc Surg 2000; 119: 155-62.

15. Liskaser FJ, Bellomo R, Hayhoe M, et al. Role of pump prime in the etiology and pathogenesis of cardiopulmonary bypass-associated acidosis. Anesthesiology 2000; 93: 1170-3.
16. Alston RP, Cormack L, Collinson C. Metabolic acidosis developing during cardiopulmonary bypass is related to a decrease in strong ion difference. Perfusion 2004; 19: $145-52$.

17. Swan RC, Pitts RF. Neutralization of infused acid by nephrectomized dogs. J Clin Invest 1955; 34: 205-12.

18. Garella S, Dana CL, Chazan JA. Severity of metabolic acidosis as a determinant of bicarbonate requirements. N Engl J Med 1973; 289: 121-6.

19. Shires GT, Holman J. Dilution acidosis. Ann Intern Med 1948; 28: 557-9.

20. Stewart PA. Independent and dependent variables of acid-base control. Respir Physiol 1978; 33: 9-26.

21. Kurtz I, Kraut J, Ornekian V, Nguyen MK. Acid-base analysis: a critique of the Stewart and bicarbonate-centered approaches. Am J Physiol Renal Physiol 2008; 294: F1009-31.

22. Svenmarker S, Haggmark S, Ostman M. What is a normal lactate level during cardiopulmonary bypass? Scand Cardiovasc J 2006; 40: 305-11.

23. Haisjackl M, Birnbaum J, Redlin M, et al. Splanchnic oxygen transport and lactate metabolism during normothermic cardiopulmonary bypass in humans. Anesth Analg 1998; 86: 22-7.

24. Takami Y, Ina H. Significance of the initial arterial lactate level and transpulmonary arteriovenous lactate difference after open-heart surgery. Surg Today 2002; 32: 207-12.

25. Toraman F, Evrenkaya S, Yuce M, et al. Lactic acidosis after cardiac surgery is associated with adverse outcome. Heart Surg Forum 2004; 7: E155-9.

26. Lemieux G, Junco E, Perez R, et al. Renal metabolism during four types of lactic acidosis in the dog including anoxia. Can J Physiol Pharmacol 1986; 64: 169-75.

27. Baretella O, Xu A, Vanhoutte PM. Acidosis prevents and alkalosis augments endothelium-dependent contractions in mouse arteries. Pflugers Arch 2014; 466: 295-305.

28. Russo MA. Dilutional acidosis: a nonentity? Anesthesiology 1997; 87: 1010-1; author reply 3-4.

29. Adrogue HJ, Madias NE. Management of life-threatening acid-base disorders. First of two parts. N Engl J Med 1998; 338: 26-34.

30. Neitzel T, Stiller M, Bushnaq H. Statistische Analyse der in Deutschland durchgeführten Perfusionen - Ergebnisse einer Umfrage 2013. Kardiotechnik 2014; 10: 12-22. 